\title{
A simple method for recording hippocampal theta in the freely moving rat
}

\author{
MELVIN L. GOLDSTEIN \\ Indiana University at Kokomo, Kokomo, Indiana 46901
}

\begin{abstract}
A method is described for recording hippocampal theta electrical activity in the freely moving rat. Bipolar recording electrodes are constructed by soldering two insulated stainless steel wires to male connectors and then twisting the two wires together. The electrodes are implanted into the rat's brain and are fastened to the skull with machine screws and plastic modeling material. A small cap is built up around the electrodes with plastic cement so that only the male connectors protrude from the electrode assembly. Female leads are connected to an EEG machine by means of microdot cable. A typical hippocampal theta recording obtained with this method is presented. This recording technique has been applied to the classical fear condtiioning technique. Preliminary results suggest that hippocampal theta may drop out after only two or three classical fear conditioning trials.
\end{abstract}

Several investigators have recently recorded hippocampal theta in the freely moving rat (Brugge, 1965), or during classical conditioning (Bremner, 1964, 1968). These experimenters have used miniature sockets as electrode holders for chronically implanted animals. The implanted electrode technique reported in this paper bypasses the use of these cumbersome miniature sockets and uses, instead, an electrode that is permanently implanted into the brain with plastic modeling cement serving as the electrode holder. A detailed report of this method has not previously been published.

Simple bipolar recording electrodes may be constructed by soldering two insulated stainless steel wires (Driver Harris Company, Harrison, N. J., Type 304, .0056 in. diam) to small male connectors (Winchester Electronics Corp., Norwalk, Connecticut, $3 \mathrm{~mm}$ long, $1 \mathrm{~mm}$ diam, catalogue No. 27023) and then twisting the two wires together.

The electrodes are implanted into the rat's brain with the aid of a Baltimore rat stereotaxic instrument. The stereotaxic coordinates used for recording hippocampal theta are: $2.5 \mathrm{~mm}$ posterior to bregma, $4.0 \mathrm{~mm}$ lateral to midline, $3.0 \mathrm{~mm}$ below the dura.

The electrodes are fastened to the skull with $1 / 8$-in.long machine screws (Gordon Engineering Co., Madison, Wisconsin, Size 2-56 stainless steel) and plastic modeling material (William Getz Corp., Chicago, Illinois). A small cap is built up around the electrodes with plastic cement so that only the male connectors protrude from the electrode assembly. Female leads (catalogue No. 27024) are

This preparation was developed with the aid of a supply grant awarded by the Indiana University Office of Research and Advanced Studies (Grant No. 26-631-32). Patricia Ward typed the manuscript.

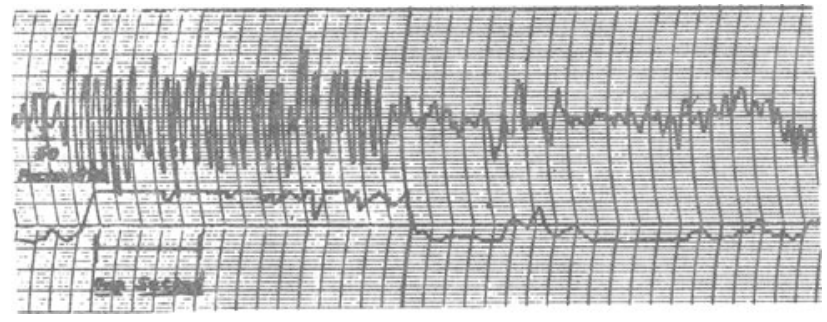

Figure 1. Hippocampal theta electrical activity in the freely moving rat.

connected to a Grass Model 7P5A EEG machine by means of microdot cable. This is an insulated cable which reduces ac artifacts. A ground electrode, connected to the skull, is also required. The entire operation takes approximately $4-5 \mathrm{~h}$.

A typical hippocampal theta recording obtained with this method is shown in Figure 1. This recording was taken from a resting animal before classical fear conditioning trials. Additional research is necessary to determine whether there is any correspondence between the occurrence of hippocampal theta and the stages of classical fear conditioning.

\section{REFERENCES}

BREMNER, F. J. Hippocampal activity during avoidance behavior in the rat. Journal of Comparative and Physiological Psychology, 1964, 58, 16-22.

BREMNER, F. J. Hippocampal electrical activity during classical conditioning. Journal of Comparative and Physiological Psychology, 1968, 66, 35-39.

BRUGGE, J. F. An electrographic study of the hippocampus and neocortex in unrestrained rats following septal lesions. Electroencephalography and Clinical Neurophysiology, 1965, 18, 36-44.

(Received for publication August 23, 1975.) 